\title{
Empirical Research on the Coupling Relationship Between P.E. Teachers Occupation Burnout and Stress Coping Styles Based on Covariation Model
}

\author{
Bofei Xie \\ Wenzhou Vocational and Technical College, Wenzhou, China \\ x_iebofei@126.com
}

\begin{abstract}
Keywords: stress coping styles; multivariate analysis; data processing; exponential fitting
\end{abstract} inspection; covariation model

\begin{abstract}
The higher vocational college sports teachers' job burnout has very important significance for today's professional colleges and universities sports education development and PE teachers' professional responsibility research. This paper firstly analysis the formation of teachers' occupational tiredness model, on the basis of it,we used the ideas of the mathematical model of teachers' occupational tiredness characteristics analysis model in higher vocational school construction, using the mathematical analysis software deep analysis of teachers' work pressure, teaching self-efficacy and coping the relationship between styles and job burnout, it is concluded that the cause of job burnout, and puts forward the related countermeasure, it provide a theoretical reference for higher vocational college PE teachers' job burnout problem.
\end{abstract}

\section{Introduction}

With the development of society, the reform of quality education is continue put forword, people gradually pay more the attention to the teacher's job burnout problem[1]. However, in our country, the research that related to teachers' occupational stress is few, especially for the o ccupational stress research of higher vocational colleges physical teachers are seem to be less. With the working pressure increases day by day, many domestic and foreign experts have done too much research on occupational tiredness.Pine and Aronson think: job burnout, it is a kind of emotional state, to meet the excessive desire to demand of resources, produce a kind of physical and mental are different from ordinary failure state, usually relevant with mental, emotional, spiritual; Brill do research on teacher burnout problem after a certain research reached a similar paper, she felt the major determinant of job burnout is spirit, the mental state influence job burnout, and produce professional burnout is no psychosis, only the normal physiological talent will produce dysphoric mood, the various aspects function of body will lose coordinated control; Mirrsi also has certain research on occupational tiredness, he take the job burnout problem as a negative reaction to the accumulation of working environment[2,3]. Cherniss closely relates job burnout and work issues together, in her understand that job burnout in general has a stress stage presence, at this stage, physiological man is in a kind of psychological and physiological which are not balanced state.

\section{The common feature analysis of job burnout}

There are a lot of reasons for the formation of job burnout, such as long time engaged in regular transverse work, work process system is extremely strict with staff, work results can not inspired the staff's work enthusiasm, frustrating, etc;Someone who engaged in the work of high tension spirit in the short term, emotional strain in working process, even in failure state, which make the person produce great feeling of fatigue; Whether long or short term work in the work process, there will be a professional aversion appear, if they can't timely transforma the thought,they would be a person continue stay in the condition of negative pressure, and its may led to bad mood,when time is long,they will produce a feeling of job burnout[4]. Whether the job burnout is , job burnout has includes the following five common features. Specific as below. 


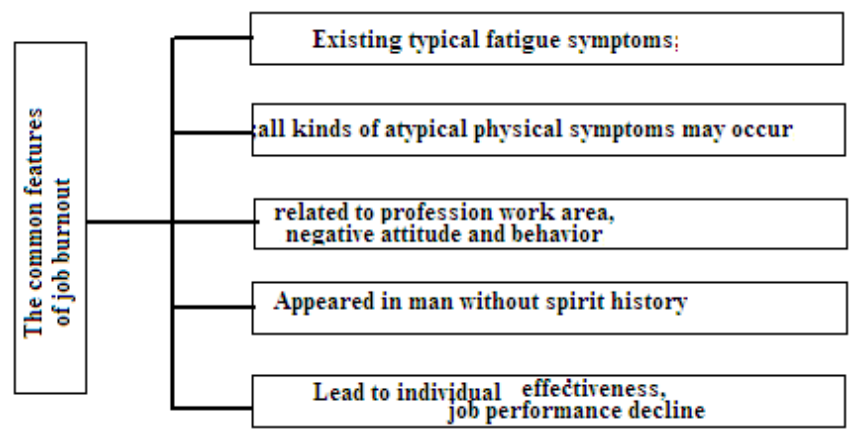

Figure 1. The common features of job burnout

The common features of job burnout: Existing typical fatigue symptoms;all kinds of atypical physical symptoms may occur; related to profession work area, negative attitude and behavior; Appeared in man without spirit history; Lead to individual effectiveness, job performance decline[5].

As shown in Figure 1, the common features of job burnout and the reasons for the formation of job burnout is closely related to the job burnout, the cause of the formation of job burnout and work, job burnout is closely related to work. the job burnout will show a personal emotional control point is low, the character is easy to appear the division, the lack of a sense of personal fulfillment in the work.

\section{The classical mode of teachers' occupational tiredness}

A. The four stage theory model of job burnout

Four stage theory model refers to divide job burnout into four stages, and the specific as below.

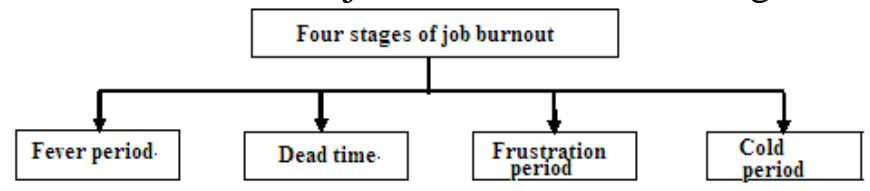

Figure 2. $\quad$ Four stages of job burnout

As shown in Figure 2, job burnout is divided into four stages are: fever period, lag phase, frustration period and cold period. The fever period is refers to the worker has just started with great enthusiasm for the work; Lag phase refers to with the work go on,the work enthusiasm wanes, the working attitude is not correct, the job satisfaction gradually reduce, job enthusiasm reduced; Frustration period refers to because of the change of someone's attitude ,they may have personal aversion, physiological, psychological and action likely to make a big change; Cold period refers to completely give up personal goal and ideal, it doesn't matter the value and meaning of life, fully drift, indulge yourself[6].

B. 3.2 The covariant model mode of job burnout

Covariant model mode means divided the human life into two stages, and peak leap forward stage and low shock stage, life is a kind of sine curve, as below.

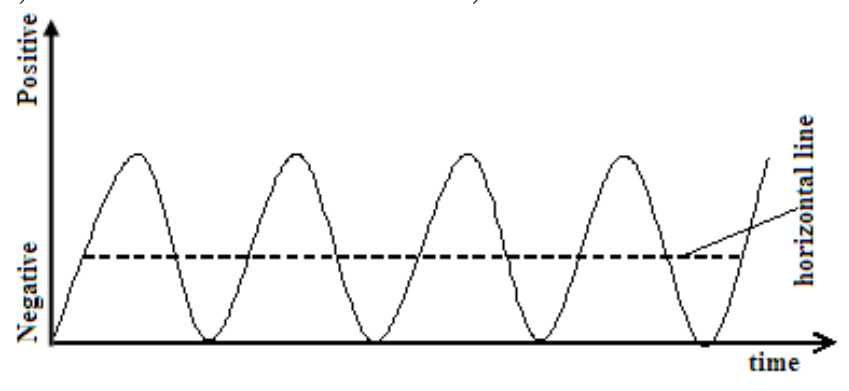

Figure 3. The job burnout covariant model mode

As shown in Figure 3, the teacher will have a positive enthusiasm in the early stages of the job, with the passage of time, they can appear the bottom changes, but after the trough they will still slowly rising own professional personal integrity, and gradually implement the education in the positive mentality. 


\section{Index fitting analysis of vocational school teachers' job burnout}

\section{A. Measurement statistical tools}

Measurement statistical tools include teachers' job burnout scale, SPSS12.0 and LISREL8.51 software tools.

B. Index fitting method

For investigative and statistical data, we use index fitting method, finally draw the curve diagram.In curve fitting we can using high order MD method of curve fitting, the specific methods are as follows[7,8]:

For the initial value problems

$$
\left\{\begin{array}{l}
\mathrm{P}^{\prime}=\mathrm{f}(\mathrm{t}, \mathrm{P}(\mathrm{t})), \mathrm{t} \geq 0 \\
\mathrm{P}(0)=\mathrm{a} 0, \text { ao } \in \mathrm{D}
\end{array}\right.
$$

Make $\mathrm{P} \in \mathrm{D}$, inductive definition[9]:

$$
\mathrm{P}^{(0)}=\mathrm{P}, \mathrm{P}^{(1)}=f(t, P), \mathrm{P}^{(\mathrm{i})}=\frac{\partial P^{(i-1)}}{\partial t}+\frac{\partial P^{(i-1)}}{\partial P} * P^{(1)}, \mathrm{i}=2,3, \ldots .
$$

Make $\mathrm{x}=2 \mathrm{p}$,to multiply $\overline{\mathrm{k} !(2 \mathrm{P}) \mathrm{p}}$ by type ends, after a series of transformation, and finally get the following formula[10]:

$$
\left\{\begin{array}{c}
\frac{a 1}{(k-1) !}+\frac{a 2}{(k-2) !}+\ldots+a k+b k=\frac{1}{k !}, k=1,2 \ldots, p \\
\frac{a 1}{(k-1) !}+\frac{a 2}{(k-2) !}+\ldots+\frac{a_{P}}{(k-P) !}=\frac{1}{k !}, k=P+1, P+2 \ldots, 2 p
\end{array}\right.
$$

C. Test the index fitting of teacher taedium vitae

In the analysis, in order to be able to effectively the index fitting of test teacher taedium vitae, we used the LISRELS. 51 software, the most popular research tool, which influence the teacher burnout influence factors in factor analysis, to the statistical analysis of the fitting index, specific fitting index statistics are shown as below.

TABLE I. The fitting index returns

\begin{tabular}{|c|l|l|l|l|l|}
\hline Questionnaire name & \multicolumn{1}{|c|}{ X2 } & \multicolumn{1}{|c|}{ dP } & \multicolumn{1}{|c|}{ X2/dP } & \multicolumn{1}{|c|}{ RMSEA } & \multicolumn{1}{|c|}{ NNFI } \\
\hline Effect sense & 179.24 & 89 & 2.01 & 0.035 & 0.97 \\
\hline pressure & 1424.8 & 621 & 2.29 & 0.011 & 0.9 \\
\hline tireness & 455.68 & 206 & 2.21 & 0.033 & 0.92 \\
\hline Simple coping styles & 221.37 & 109 & 2.03 & 0.051 & 0.92 \\
\hline
\end{tabular}

Higher vocational colleges need to focus on the development of interpersonal relationship, constructing the harmonious development of the interpersonal relationship, thus forming a harmonious and efficient social support type interpersonal network. Give teachers' active help and counseling from psychological, make teachers' active face the setbacks, searching for the best solution of the problem in the difficulty, reduce and avoid the emergence of job burnout.

\section{The characteristics of higher vocational college PE teachers' job burnout}

In the long-term work ,Physical education teachers in higher vocational colleges,they have to face a single work object, feeling into huge, its emotional demand is rich, which can lead to personal feelings very failure, mental ability depletion; The lack of affection can lead to physical education teachers produce a ring of encirclement in real life, living in their own circle, gradually appeared from groups, split personality; Finally, job burnout in burnout status in life for the long-term, personal achievement is reduced, work efficiency descend. Higher vocational colleges and universities sports teacher teacher burnout situation analysis shown as table 2.

TABLE II. The analysis table of teacher burnout situation

\begin{tabular}{|c|c|c|c|}
\hline & $\mathbf{N}$ & Mean(\%) & Dimension difference(\%) \\
\hline Emotional reduction & 735 & 2.68 & 0.83 \\
\hline deindividuation & 735 & 2.12 & 0.9 \\
\hline Achievement recession & 735 & 2.56 & 0.69 \\
\hline
\end{tabular}

From Table 2, it is known that the higher vocational college PE teachers' emotional lower average 
are on the high side, compared with deindividuation,they obvious nearly $5 \%$ higher ,and a sense of accomplishment recession and emotional shock lower are almost in equal level.

Through the exponential curve fitting method, we can get a series of teachers' job burnout situation tables and charts, and find out the reason of the job burnout, and finally puts forward some relevant countermeasures, provide a theoretical reference to higher vocational college PE teachers' job burnout problem[11]. And put forward effective and targeted solutions and countermeasures, and to effective explore the causes and characteristics of higher vocational college PE teachers' job burnout, then adjust and perfect them. Through the cognition of vocational education mode, we can create a good learning and working environment to assit teachers to adjust a positive attitude.

\section{The coupling relationship analysis of stress coping styles and job burnout}

Vocational college teachers is different from other school teachers, because of the attention of the assessment results and the urgent need to improve graduation rates, long-term in a high pressure working condition is also one of the reasons for the teachers' occupational tiredness[12]. Teacher's job burnout is also directly reaction in daily teaching activities, and teaching, learning, and finally results in the construction of the whole school and style.

Domestic and international numerous research results show that the leadership and teaching management mode will have direct influence to teacher working atmosphere and personal growth. Help teachers relief work pressure, maintain teachers' job emotional stability, full of vigor into the education teaching, so as to reduce or even eliminate the occupational tiredness. It is not hard to find the way to cope with the pressure and the coupling relationship between job burnout is a monotone decreasing function, so the stress coping styles and maximum allowable of job burnout under the premise of increasing the coupling coefficient between them as far as possible to reduce ${ }^{Q(L)}$.In the the study course of the vocational school teachers' professional characteristics we can find that job burnout problem commonly existed in all kinds of teachers. Keep the teachers' teaching environment and atmosphere good is a way to alleviate and eliminate job burnout, and are the premise and basis to promote the teaching more efficient. Below we are consider from analyzing the view of effect point, we take $Q(0)=k_{1}-\frac{T_{1}-T_{2}}{2 d}$ as the reference,made the following foumula[13]:

$$
h(l / d)=1 /\left(\frac{k_{1}}{2 k_{2}}-\frac{1}{d}+1\right)
$$

In the education teaching practice, grasp the good opportunity of the new situation, to provide more learning opportunities for teachers, emphasize teachers' properties, improve teachers' teaching enthusiasm, make the teacher in the process of professional obligations, access to professional sense of identity and pride, and the teaching environment, content, pattern, purpose belonging and sense of worth, improve the sense of teaching effectiveness of vocational education mode, to reduce the purpose of job burnout. At this time,

$$
h(l / d)=1 /\left(8-\frac{1}{d}+1\right) .
$$

Stress coping styles and job burnout coupling effect as below.

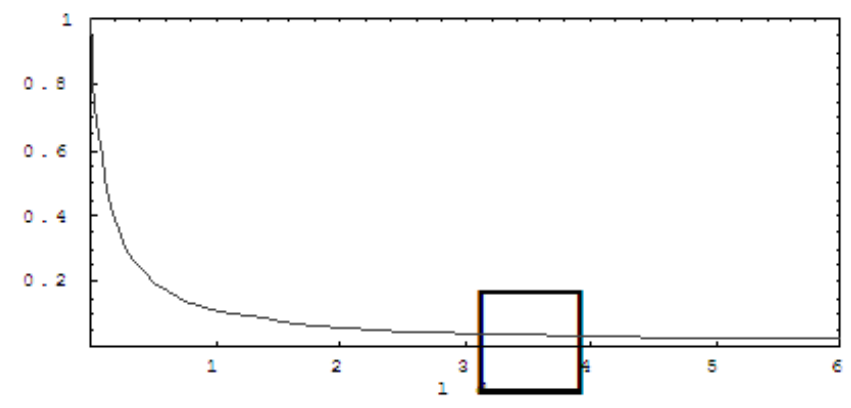

Figure 4. The pressure coping styles and job burnout coupling function curve 
As you can see above, when $\boldsymbol{I}$ increase from 0 , the curve fell rapidly, especially at that time $\boldsymbol{l}=\mathbf{4} \boldsymbol{d}$, appropriate adjust the state, averagely distribute the work task, disperse and relief the teachers' work load, looking for more efficient mode of management, balance teachers' physical and mental development, promoting teachers keep career expectations and enthusiasm. For the realization of the need of vocational colleges physical education teachers in teaching, scientific research and the recreational activity, etc, should be full implement the teaching management democratization and human life management. School department leaders should pay more attention to scientific which can guide teachers to carry out education teaching work, mining potential teachers, arouse the enthusiasm of teachers to professional.

\section{Conclusion}

In the high-speed development of modernization, social life change with each passing day today, the teacher need to keep learning knowledge, improve various aspects ability, positive enterprising, so as to better adapt to the development of modern society changes. The teacher can positive adjust the attitude from the following four aspects: keeping pace with the Times, constantly breakthrough oneself; Realistic and innovative, diversified develop teaching way; Stay healthy and strengthen daily exercise, in the most full of energy to deal with the teaching activities of the multifarious tasks; Gentle state of mind, keep the best working condition in the education teaching process. Maintain a positive teaching enthusiasm and efficient teaching behaviors is the premise and foundation to eliminate teachers' occupational tiredness.

\section{References}

[1] Bian Ranlong, LiRong. Job burnout theory research and development. Chinese journal of clinical psychology, 2010 (4) : 17-20.

[2] Li Peizhong. Job burnout theory research and countermeasures. Journal of liaoning college (social science edition), 2011(8):34-37.,

[3] Su Sumei. The discussed of the teacher's job burnout.Journal of education material abstract, 2010(3) : 9-17.

[4] Zeng Lingjuan, $\mathrm{Wu}$ Xinchun. The research summary of teachers' job burnout.Journal of education research, 2008 (11) : 79-81.

[5] Tang Fanggui, Jiang Li , Xiao Zhicheng. Foreign teachers' occupational tiredness review study . Education and occupation, 2009 (5) : 65-67.

[6] Chen Mingli, Xu Ming. Teachers occupational stress research in overseas . Journal of fujian normal university (philosophy and social science edition), 2010(3) : 123-129.

[7] Shi Lin,Xu Ming. Pressure and health . China light industry press, 2010:345-357.

[8] Wang Zhenhong. Foreign teacher effectiveness research review. Psychology dynamic, 2011 (2) : 146-150.

[9] Zhong Xuliang, Xu Fuming, Zhu Congti. Teachers occupational stress and coping strategies . Management of primary and secondary schools, 2012(2):15 - 16.

[10] Wu Guolai, Wang Guoqi. White self-efficacy and sense of teaching effectiveness review .Journal of BaoDing normal school journal, 2012 (7) : 74-77.

[11] Xu Fuming, Zhong Jiliang. The relationship research for Teachers occupational stress coping strategies and teaching efficiency .journal of psychological science, 2008(6) : 45-46.

[12] Ye Yituo,Zhong Yane. Deal with and coping styles in study .Journal of psychological science, 2012 (2) 55-56.

[13] Hou Wei, Li Yongxin. Teachers' occupational tiredness research in Taiwan. Journal of AnYang normal university, 2009(9):45-49. 